\title{
A ELEGIA À AMIZADE DO PADRE CALDAS, UM PONTO FORA DA CURVA
}

\author{
FATHER CALDAS' ELEGIA À AMIZADE, AN OUTLIER \\ CASE
}

Gabriel Esteves*

Resumo: O objetivo deste trabalho é mostrar como a Elegia à amizade, poema publicada por Antônio Pereira de Sousa Caldas em 1821, se destaca do longo panorama de elegias escritas em língua portuguesa entre os séculos XVI e XVIII pela atípica abordagem de um tema estranho ao que se convencionou chamar "poesia elegíaca" na modernidade. Para tanto, divido meu argumento em duas partes: na primeira, traço um breve percurso das transformações sofridas pelas elegias de língua portuguesa até o momento em que a obra de Sousa Caldas foi publicada. Na segunda, me debruço sobre a própria Elegia à amizade com o fim de destacar suas características excepcionais e os pontos em que dialoga com as tradições latina e vernacular.

Palavras-chave: Elegia; Sousa Caldas; classicismo.

Aвstract: The objective of this work is to show how the Elegia à amizade, a poem published by Antônio Pereira de Sousa Caldas in 1821, stands out from the long picture of elegies written in Portuguese between the 16th and 18th centuries by the atypical approach to a theme foreign to what has been agreed to call "elegiac poetry" in modern times. For that, I divide my argument in two parts: in the first, I trace a brief overview of the transformations undergone by the Portuguese-language elegies until the moment when Sousa Caldas' work was published. In the second, I look at the Elegia à amizade aiming to highlight its exceptional characteristics and the points in which it dialogues with the Latin and vernacular traditions.

KEYwords: Elegy; Sousa Caldas; Classicism.

"Doutorando do Programa de Pós-Graduação em Literatura da Universidade Federal de Santa Catarina, bolsista CNPq e
membro do Núcleo de Pesquisas em Informática, Linguística e Literatura - NuPILL. E-mail: gabrielesteues@gmail.com. 


\section{INTRODUÇão}

Em 1821, veio à luz o segundo tomo dos poemas sacros e profanos compostos pelo reverendo Antônio Pereira de Sousa Caldas. O livro, postumamente organizado pelo "sobrinho do defunto poeta" e publicado em Paris, foi lido, admirado e emulado por alguns dos nossos primeiros românticos, o que valeu a Sousa Caldas um lugar no Parnaso Brasileiro (1843) de Manuel Pereira da Silva e um posto como patrono da cadeira de número 34 da Academia Brasileira de Letras. Obras como a Ode ao homem selvagem e a Carta dirigida a meu amigo João de Deus Pires Ferreira, contidas neste livro, se tornaram referenciais - essa segunda, vale lembrar, chegou mesmo a entrar para a antologia da poesia brasileira de invenção proposta por Haroldo de Campos em A arte no horizonte do provável (1969). Mas não é a respeito dessas famosas composições que pretendo escrever, e sim sobre uma pequena, ofuscada Elegia à amizade. Ao longo deste trabalho, ${ }^{1}$ será meu objetivo mostrar como essa peça, quando contrastada às outras elegias escritas em língua portuguesa entre os séculos XVI e XVIII, se destaca pela atípica abordagem de um assunto estranho ao que se convencionou chamar "poesia elegíaca" na modernidade. Na primeira parte deste estudo, traçarei um breve percurso das transformações sofridas pela elegia de língua portuguesa até o momento em que a obra de Sousa Caldas é publicada. Na segunda, me debruçarei sobre a própria elegia, mas sem a intenção de esgotar a sua análise ou propor uma interpretação total e fechada.

\section{Breve panorama da elegia de língua portuguesa}

\section{Quinhentistas}

Praticamente todas as peças quinhentistas que se apresentam como elegias são escritas em tercetos rimados, ${ }^{2}$ à maneira italiana, e grande parte delas tem a morte como ponto de partida. Há, contudo, algumas ressalvas: i) nem todo poema escrito em tercetos é elegia; ii) nem todos os poemas fúnebres são escritos em terza rima ou apresentados como elegias; iii) nem toda elegia trata de assunto fúnebre. Pedro de Andrade Caminha, por exemplo, ao lado das conhecidas elegias fúnebres, compôs nada menos que treze elegias amorosas ao gosto romano, dedicadas todas a Fílis (também evocada, não por acaso, nos Aitia de Calímaco e nas Heroides de Ovídio), e outras tantas traduções em tercetos que fazem o amor de tema central (são as elegias Marcos e Vênus, Angeriano e Amor e Amor perdido):

\footnotetext{
${ }^{1}$ Este trabalho foi realizado com apoio do CNPq, Conselho Nacional de Desenvolvimento Científico e Tecnológico - Brasil. ${ }^{2}$ Possíveis exceções são peças como Penas amorosas, Labirinto de amor e o soneto dedicado à morte do príncipe Dom João, inseridas como elegias na coleção de Pedro de Andrade Caminha de 1791, mencionada na bibliografia. A julgar, no entanto, pela coesão entre elegia e terza rima na obra dos demais poetas quinhentistas, essas atribuições me parecem um tanto quanto questionáveis.
} 
Não sei se de ti só, Fílis, me queixe,

Se de mim, se de Amor, se da ventura,

Ou se de todo meus queixumes deixe.

Sinto a pena que passo, áspera e dura, Sem nunca me deixar um só momento, Causada só da tua fermosura.

Vejo em mim sempre vivo o gram tormento Que em ti só tem remédio e se me nega, Nem vê ũa só esperança o pensamento. (CAMINHA, 1898, p. 155)

Diogo Bernardes segue a mesma trilha: todas as cinco elegias compiladas no seu volume de Rimas várias falam do padecimento provocado pelo amor de Sílvia. A elegia III de Antônio Ferreira parece se ater às mesmas influências, embora as incorpore de maneira mais aberta, alegre, e um tanto quanto panorâmica - trata-se de uma exortação ao mês de maio e aos amores primaveris que, a não ser pela forma tipicamente elegíaca, poderia se passar por ode:

Vem Maio de mil ervas, de mil flores

As frontes coroado, e riso e canto

Com Vênus, com Cupido, com os Amores.

Vença o prazer à dor, o riso ao pranto;

Vá-se longe daqui cuidado duro,

Enquanto o ledo mês de Vênus canto.

(FERREIRA, 1875, p. 84)

Nessas composições, Caminha e Ferreira acenam para a musa leve da elegia latina, segundo a cultivaram poetas da estirpe de Tibulo, Propércio e Ovídio. Os romanos, como se sabe, fizeram da elegia um campo fundamentalmente erótico, jocoso e ocioso (no sentido latino), o que foi muitas vezes descrito pelos tratadistas posteriores como uma excentricidade, quase como um desvio da natureza do gênero. Assim, Caminha, falando incessantemente dos sofrimentos causados pelo amor ingrato de Fílis, lembra Tibulo a respeito de Délia (no primeiro livro do Corpus Tibullianum) e Nêmesis (no segundo), Propércio a respeito de Cíntia (ao longo dos livros I e II de sua obra) etc.; Ferreira, manejando os intrincados campos semânticos do amor e da vida rural, tratando a primavera como uma estação fértil, pacífica, avessa ao sofrimento e à dor, faz pensar, sobretudo, em Tibulo. Ou seja, se nossos quinhentistas portugueses não chegam a acrescentar novos temas ao inventário criado pelos seus ancestrais, ao menos fazem um aceno às possibilidades conhecidas do gênero. Não se esquecem, assim, de que a vetusta elegia já serviu para cantar a paz e os amores - e mais: a elegia VI de Antônio Ferreira, por exemplo, dedicada a Afonso d'Albuquerque, é antes um canto heroico e laudatório do que 
propriamente fúnebre - nas palavras de Júlio de Castilho (1875, p. 79): "versos sonoros, grande altiloquia, patriotismo e calor poético, tais são os predicados de tão notável peça”. A não ser pela forma, também passaria por ode. Não se pode deixar de pensar na possível influência de um Tirteu ou de um Calino - aliás, dois dos primeiros poetas elegíacos de que temos conhecimento, e que não nos legaram nenhuma composição lamuriosa.

As elegias de Camões, por sua vez, são filosóficas, pesarosas, religiosas (como, aliás, aquelas compiladas por Diogo Bernardes em Várias rimas ao bom Jesus), por vezes amorosamente tristes, e algumas chegam mesmo a ostentar um tom narrativo que beira aqui a égloga, ali a épica. Elas compõem um universo à parte, unido pelo cultivo da terza rima. Agora, francamente fúnebre, há apenas uma: a elegia X a Dom Miguel. A primeira da série, vale lembrar, faz referência direta a Ovídio, mas não ao cantor dos amores, o tenerorum lusor amorum, e sim ao poeta desterrado das Tristia e das Epistulae ex Ponto, ${ }^{3}$ justamente porque Camões se encontrava na mesma situação de degredo, assolado pelas saudades de casa.

Vemos, assim, que embora todas as peças que mencionei tratem de assuntos distintos, às vezes mais sérios, às vezes menos, elas compartilham uma mesma forma: são escritas em terza rima. Deduz-se daí que o critério distintivo do gênero elegíaco para os portugueses do século XVI é antes formal do que temático. Em outras palavras, se um poema se apresenta como elegia, é grande a chance de que ele esteja distribuído em tercetos rimados, mas não é certo que seu tema seja fúnebre; o corpus de elegias amorosas passa longe de ser desprezível. Não é certo, por outro lado, que um poema em tercetos rimados seja elegia, e há mesmo situações em que não é possível afirmar a qual gênero pertence a obra que temos diante dos olhos - há poemas de Sá de Miranda escritos em terza rima, por exemplo, que aparecem em algumas coleções como cartas e em outras como elegias; é o caso da peça A uma senhora muito lida em nome de um seu servidor e daquela que se inicia com o verso Monte mayor, que a lo alto del Parnaso. ${ }^{4}$ A associação entre elegia e terza rima, em todo caso, foi notada e descrita por um dos mais esclarecidos tratadistas portugueses do século XVIII, Francisco José Freire, ou, como ficou conhecido, Cândido Lusitano. Em sua Arte poética (1749), Freire explica que a alternância entre rimas pares e ímpares típica dos tercetos é uma tentativa de adaptar a sucessão entre versos hexamétricos e pentamétricos às línguas modernas:

Seguiremos, pois, com muitos autores, a [definição] do Padre Donato, que a [elegia] define: Poema, quod solum hexametro et pentametro versu conficitur. Estes versos, já se sabe que hão de ser alternados de tal modo que sempre ao hexâmetro suceda o pentâmetro, e é tão própria esta

\footnotetext{
${ }^{3}$ A emulação dessas epistulae escritas em dísticos elegíacos, convém destacar, me parece estar por trás da grande quantidade de cartas escritas em terza rima durante o século XVI.

${ }^{4} \mathrm{Na}$ edição de 1784, impressa na Tipografia Rolandiana, essas peças são cartas; na edição de 1804, feita pela Impressão Régia, a primeira é elegia e a segunda não tem gênero especificado, embora se insira na seção de elegias. É possível que a confusão se dê pela ausência de um motivo fúnebre, pois as elegias trocadas entre Antônio Ferreira e Sá de Miranda a respeito da morte do filho deste não a sofrem, apesar de possuírem um caráter evidentemente epistolar.
} 
alternativa que até na elegia vulgar se usa dela, correspondendo sempre o consoante do primeiro verso de um terceto com o do terceiro verso do mesmo terceto, e o do segundo verso do primeiro terceto com o primeiro do segundo terceto. (FREIRE, 1749, p. 383)

Sua constatação (plenamente verificável, como vimos) condiz com a prática dos poetas portugueses e sugere que a elegia moderna, a exemplo da antiga, possuía uma forma fixa, ainda prescrita na alvorada do século XIX. ${ }^{5}$ Seguiram-na os contemporâneos do tratadista?

\section{NEOCLÁSSICOS}

Os árcades portugueses d'aquém e d'além mar foram pobres elegíacos, mas se ativeram à prática dos tercetos. Alcipe, a marquesa de Alorna, compôs algumas pomposas elegias de ocasião - todas fúnebres. Bocage fez o mesmo, incorrendo vez ou outra em pesarosas reflexões. Os poetas deste lado do Atlântico não fizeram mais pelo gênero. Cláudio Manuel da Costa prefere, para tratar motivos fúnebres, os epicédios às elegias. Gonzaga, Basílio da Gama e Alvarenga Peixoto não as escrevem de todo. Manuel Inácio da Silva Alvarenga, embora não componha elegias, lança mão da terza rima para escrever uma heroide de franca inspiração ovidiana (e elegíaca, portanto), Teseu e Ariadne, além de alguns idílios e églogas, como Cláudio Manuel da Costa, a que acrescenta estrofes variadas. Há poucos sinais, portanto, da musa erótica latina. A elegia perde espaço e perde assuntos. Assim ela foi, pouco a pouco, se tornando um gênero convencional e prescindível, estritamente ligado à morte, ainda que Francisco José Freire, pela mesma época, se empenhasse em demonstrar a riqueza de sua gama temática:

Não especificou o autor desta definição [Padre Donato, citado acima] que a elegia era um poema triste, porque falou como devia ser, da elegia moderna, que não só, como a antiga grega, compreende cousas fúnebres, mas também amores, guerras, louvores, vodas [sic], triunfos, congratulações e, finalmente, quase todas as matérias. (FREIRE, 1749, p. 383)

Foi embalde. Folheando os outros manuais da época, tem-se uma ideia mais nítida da crescente restrição do universo elegíaco a assuntos sorumbáticos. O manual literário de Pedro José da Fonseca, por exemplo, Elementos da poética (1765), esclarece que a elegia é, a princípio, um gênero adequado apenas às tristezas - o que, vale lembrar, não pode ser verificado através

\footnotetext{
${ }^{5}$ Veja-se, por exemplo, o manual de Juan Francisco Masdeu, Arte poética fácil (1801, p. 144): "el metro de la elegía (que es lo mismo que decir su construcción poética) suele ser el de las estancias de tres versos, todos ellos de once pies, y con consonante que pasen de una estancia a la otra hasta el fin de la poesía, en que se pone un verso solitario que consuene con el penúltimo".
} 
de uma pesquisa empírica (como bem notou Cândido Lusitano ${ }^{6}$ ), pois as primeiras elegias gregas a que temos acesso não são propriamente fúnebres:

A elegia, como o seu mesmo nome indica, servia unicamente em seus princípios a assuntos tristes, dos quais, segundo alguns pretendem, passou depois a empregar-se também nos alegres. Tibulo, Ovídio e Propércio foram os que a reduziram aos interesses do amor e à sua imitação todos os demais latinos, pois ou estes louvassem os prazeres, ou chorassem os males da guerra, sempre encaminhavam tudo aos seus amores. (FONSECA, 1765, p. 323-324)

Assim, o assunto da elegia deve, apesar dos poemas de Arquíloco, Sólon, Tirteu, Calino, Xenófanes, Mimnermo, Calímaco e outros mais, se limitar a "tudo que for funesto e cheio de tristeza" (ibid, p. 325), ou, nas palavras de Juan Francisco Masdeu já nos primórdios do século XIX: "[la elegía] es una poesía en que se llora una muerte, un naufragio, una desgracia, un objeto de melancolía, cualquiera que sea" (1801, p. 143-144). Quanto à eventual abordagem de assuntos eróticos difundida pelos elegíacos latinos, deve se restringir, a fim de preservar o caráter supostamente verdadeiro do gênero, apenas aos mais violentos amores: "ainda mesmo o amor, a ser tranquilo e satisfeito, se deve excluir, deixando-lhe meramente o zeloso, inquieto e com furor, para assim reduzir a elegia ao seu verdadeiro caráter" (FONSECA, 1765, p. 325). O que pensava Fonseca de uma elegia como a de número 5 do primeiro livro dos Amores de Ovídio, no entanto, em que o poeta faz da possessão amorosa uma banalidade, mera diversão para passar a tarde, ou de uma elegia tão ingenuamente alegre como aquela em que Antônio Ferreira dá boas-vindas à primavera, é algo que, infelizmente, não se pode saber.

\section{PRINCÍPIO DO SÉCULO XIX}

Ao longo da primeira metade do século XIX, a elegia se dilui num adjetivo qualitativo estreitamente associado ao lamento fúnebre e perde a sua habitual disposição em tercetos rimados. Em outras palavras, a elegia se dilui formalmente e se restringe tematicamente: pode ser um punhado de qualquer verso ou prosa, contanto que seja triste e, de preferência, reflexivo. Quem folheia os jornais do tempo se depara com sonetos, nênias, quadrinhas heptassilábicas, decassílabos brancos e outros versos “de tom elegíaco”, quer dizer, de tom fúnebre,

\footnotetext{
${ }^{6}$ Francisco José Freire destaca que não conhecemos as primeiras elegias gregas e não sabemos, de fato, quem as criou: "uma das grandes perdas que tem experimentado a poesia é não haver elegia alguma grega, segundo a sua primeira origem, que, como dissemos, foi excitar mais a compaixão que o gosto, e a piedade [mais] que a admiração" (FREIRE, 1749, p. 385). Para descrever o caráter primitivo da elegia, ele se apoia principalmente sobre o testemunho de Horácio.
} 
melancólico..$^{7}$ Pouquíssimas são as variações. ${ }^{8}$ Eduardo de Faria, em seu Novo dicionário da língua portuguesa (1859 [1849]), resume o gênero da seguinte maneira:

Elegia, s. f. (Lat., do gr. elegheion, versos tristes, de élegos, canto lúgubre, lamentação. Vem de he ou che, som imitativo do pranto, do soluçar de quem chora, [...]) poema de curta extensão, terno, triste e patético. As lágrimas, os queixumes, os pesares, os receios, as saudades que costumam acompanhar os amantes são os assuntos ordinariamente consagrados à elegia. (FARIA, 1859 [1849], p. 1195)

Nesse contexto, tudo se reduz à tristeza - até mesmo os amores. Da leve musa latina, tão vasta e permissiva, quase nenhum rastro. Em 1834, AÁguia (jornal português que também circulava no Brasil) chega a sugerir que mais vantajoso seria, "para o nosso tempo", traduzir as elegias de Ovídio em canções ou liras, pois "elegias não são entre nós o que eram entre os antigos” (AMORES DE OVÍDIO, 1834, p. 243). De fato, o jornal leva a proposta a cabo: transforma-se a elegia XI do livro III dos Amores numa canção em versos hexassílabos e quadras rimadas. O gesto seria repetido pela Íris em 1848, quando vem à luz uma tradução da elegia segunda do primeiro livro - desta vez em estrofes com cinco versos hexassilábicos, pobremente rimados. ${ }^{9}$ "Elegíaco" de verdade será o tom meditabundo das sorumbáticas poesias de Gonçalves de Magalhães - Machado de Assis, vale lembrar, o define como poeta "essencialmente elegíaco" na crítica às suas obras teatrais -, ou o aspecto rotineiramente tristonho do Livro Negro de Casimiro de Abreu, cujo subtítulo é, justamente, "poesias elegíacas".

A elegia, assim, não é mais vista como um gênero, mas como uma certa atmosfera caracterizada pela seriedade, pela melancolia e pela filosofia, perfeitamente reprodutível em qualquer formato textual. É nesse ambiente de progressiva diluição formal e restrição temática que a Elegia à amizade de Sousa Caldas é publicada.

\section{A ELEGIA DE SOUSA CALDAS}

Antes de mais nada, vamos ao texto. Retirei-o do segundo tomo das Poesias sacras e profanas do Reverendo Antônio Pereira de Sousa Caldas (CALDAS, 1821, p. 147-150) e atualizei sua

\footnotetext{
${ }^{7}$ Também há elegias satíricas e cômicas como a famosa Elegia à morte da Crônica Constitucional de Lisboa, de Antônio Feliciano de Castilho, mas que ainda preservam o aspecto fúnebre associado ao gênero.

${ }^{8}$ Veja-se, à guisa de exemplo, o pomposo poema em decassílabos brancos intitulado Versos elegíacos, e publicado anonimamente n'O Pão d'Assucar de 6 de novembro de 1835. Esta "elegia" é, a princípio, um lamento pela situação anárquica experimentada pelo Brasil em princípios do século XIX, mas logo se transforma numa exortação a que povo e poderosos, a fim de recuperar a pátria perdida, reajam contra a tirania, a discórdia e quejandos inimigos - aqui entram todas as pedras de toque do tempo, e que ainda revelam a forte influência do arcadismo português: a Lei, a União, a Liberdade, a Ordem etc.

${ }^{9}$ Cf. TRADUÇÃO DA ELEGIA SEGUNDA DO LIVRO PRIMEIRO DOS AMORES DE OVÍDIO. Íris: periódico de religião, belas-artes, ciências, letras, história, poesia, romance, notícias e variedades. Volume 1. Rio de Janeiro: Tipografia de L. A. Ferreira de Menezes, 1848, p. 259-260.
} 
grafia. Quanto à pontuação, optei por preservá-la como aparece na edição de 1821 a fim de evitar a atribuição pessoal de sentido a períodos de interpretação controversa, uma vez que, no século XIX, a sua aplicação podia estar ligada não à sintaxe, mas à intensidade das pausas e à entonação dos versos:

\section{ELEGIA À AMIZAdE}

Dirigida ao doutor Francisco José de Almeida, nela designado pelo nome de Fileno.

Estrofe I Quanto é doce existir! Quanta doçura

Em ti encerras, preciosa vida,

Inda mesmo em momentos de amargura!

II Sagrados Deuses, e hei de ver perdida

Esta fonte de bens e de prazeres,

Entre as garras da morte enfurecida?...

III Não vos invejo, soberanos Seres,

Os bens que possuis; só vos invejo

O não teres receio de os perderes.

IV Ternos Pastores do aprazível Tejo, Alegrai-vos comigo: horas amáveis, Parai; obedecei ao meu desejo.

V Da cândida amizade as mãos afáveis Sinto animar-me; e já na erguida frente Ela me imprime beijos adoráveis.

VI Tu me afagas, ó Deusa!... Céus!... Que enchente

De graças lhe atavia o meigo rosto, E da boca lhe sai tão docemente!

VII Sim: amigos achei; fuja o desgosto

Sobre as asas do Tempo fugitivo,

E na terra não torne a achar mais posto.

VIII O Fado, noutro tempo, injusto, e esquivo

Fez-me beber no cálix da desgraça

Mil desprazeres de amargor ativo.

IX Esgotei, é verdade, a horrível taça:

Mas ao tragar do fel, terna amizade

Achei; ter já não temo a sorte escassa. 
$\mathrm{X}$ Dos beiços teus pendendo, a suavidade

Meus trabalhos adoça; não te excede

Dos favos de Hibla a doce amenidade.

XI Junto a ti não receio fome ou sede;

Pois, com armas singelas a Virtude

De encarar-me ferozes, as impede.

XII Nos altos tetos, no penhasco rude,

Se a meu lado te encontro, da tristeza

Recear o semblante nunca pude.

XIII Meu querido Fileno, a Natureza

Esmerou-se em formar-te; no teu peito

Unindo dotes de imortal beleza.

XIV A ternura beijou teu brando aspeito;

E dos seus lábios o sinal gravado

Infunde puro amor, puro respeito.

XV De ti para mim voa o delicado

Sentimento, com sua mão mimosa

Polindo um coração por ti formado.

XVI Seu tato é tão macio como a rosa

De transparente orvalho rociada,

Quando a bafeja Fílis amorosa.

XVII Amizade fiel tão desejada,

Tu não existes só na fantasia;

Tu não és uma fábula sonhada.

XVIII Enchei-vos, rios, montes, de alegria;

Senti um pouco do prazer, que abala

Minhas entranhas neste claro dia.

XIX Loucos Amantes, vosso peito estala

Nos braços do ciúme roedor,

E em vós a paixão cega é só quem fala.

XX Se assim mesmo prezais esse furor,

Que a razão desaprova, sede embora

Escravos do tirano Deus do Amor. 
XXI Fileno, a tua voz encantadora

Faze soar, verei baixar a ouvir-te

A Razão, que tua alma tanto adora.

XXII A sublime Razão que fez sentir-te

O veneno cruel, que Amor encobre

Nas setas com que já soube ferir-te.

XXIII Ah! Trinta vezes seus prazeres dobre

Esse louco rapaz; terna Amizade!

Eu não o temo; o braço teu me cobre.

XXIV Das almas puras pura Divindade, Escuta-me benigna: dize, a Morte Não poupará Fileno?... Céus! Piedade!

XXV Dize-me, acaso a desabrida sorte, Antes que eu desça à fria sepultura Desferirá contra ele o final corte?

XXVI E como poderei sua figura Ver em medonho féretro estendida, Tinta da cor da pálida amargura!

XXVII Seus olhos... seu esp'rito... Ó desabrida Imagem, de mim foge: que eu não posso Suportar tão pungente, atroz ferida.

XXVIII Deusa que imperas sobre o peito nosso, Ouve os meus rogos: assim cante a Terra Sempre louvores ao império vosso.

XXIX Os meus gemidos no teu seio encerra:

Escuta, ó Deusa: no fatal momento, Que em si do meu Fileno a morte encerra, Faze que eu também lance o último alento.

Comecemos pela forma. Provavelmente escrita ainda no século XVIII, a elegia de Sousa Caldas segue a disposição canônica vernacular em terza rima que, conforme esclarecimento dado pelo manual poético de Francisco José Freire, tenta emular os antigos dísticos elegíacos e foi amplamente cultivada pelos poetas portugueses, de Sá de Miranda a Bocage. Note-se que todos os tercetos são consideravelmente independentes, e que cada um deles possui uma ideia estendida pelos três versos. Esse procedimento, já desde Dante cultivado fora do gênero 
elegíaco, parece ter sido prescrito por tratadistas e professores da época, pois Pedro José da Fonseca (1765, p. 328) se opõe à usança:

Alguns querem que na elegia latina se inclua, em cada dístico, à imitação de Ovídio, algum sentido completo, e que no pentâmetro haja sempre as mesmas cadências; porém, tanto uma, como outra cousa produziria, de necessidade, uma afetação em tudo oposta ao caráter da elegia, onde as paixões querem ser exprimidas com atividade e largueza.

As prescrições são perfeitamente estendíveis à unidade equivalente na elegia vernácula, quer dizer, aos tercetos. O fato de Sousa Caldas empregá-las indica uma sólida formação acadêmica e sugere que seu poema também deve manter comércio com a tradição do gênero no que diz respeito ao conteúdo. Uma rápida vista de olhos já é suficiente para nos depararmos com as palavras "Fílis" (uma das protagonistas das Heroides ovidianas, amada de Caminha, como vimos, e personagem na obra de vários poetas latinos), "Amor" e "Amantes", o que revela que Sousa Caldas tinha a intenção de estabelecer um diálogo com a tradição erótica latina. Esta não é, contudo, uma elegia sobre amor ou sobre o sofrimento que tão de perto acompanha a paixão elegíaca, mas uma apologia à tranquilidade da amizade. Aí está a sua originalidade. Posto contra o panorama histórico das outras peças que, na literatura de língua portuguesa, se apresentam como elegias, a peça de Sousa Caldas possui a excentricidade de abordar a amizade como tema central e alternativa salutar ao amor:

Amizade fiel tão desejada,

Tu não existes só na fantasia;

Tu não és uma fábula sonhada.

Enchei-vos, rios, montes, de alegria;

Senti um pouco do prazer, que abala

Minhas entranhas neste claro dia.

Loucos Amantes, vosso peito estala

Nos braços do ciúme roedor,

E em vós a paixão cega é só quem fala.

Se assim mesmo prezais esse furor,

Que a razão desaprova, sede embora

Escravos do tirano Deus do Amor.

O fundo mítico do poema, assim, se desdobra num combate metafórico entre duas divindades: a Amizade e o Amor. Enquanto a primeira se funda na fidelidade, na alegria, na paz e na razão, o segundo produz "loucos amantes", "escravos do tirano Deus do Amor", movidos pelo "furor" de uma "paixão cega" e um "ciúme roedor". O poeta não desconhece a tristeza 
(vide estrofes VIII e IX), e por isso mesmo expõe o receio de que o seu atual estado de alegria (vide estrofes IV-VII e XVIII), alcançado a duras penas e somente amparado pela amizade que o une a Fileno (nome genericamente árcade, aliás, empregado por vários poetas), se veja irreparavelmente danificado pelos dardos do Amor. Pede-se ao amigo, então, que evoque a sublime Razão a fim de identificar e, presume-se, remediar "o veneno cruel que Amor encobre / Nas setas com que já soube ferir-te" (estrofes XXI e XXII) - o que não deixa de ecoar os Remedia Amoris de Ovídio. Na elegia de Caldas, amor e morte se encontram e se identificam: amar é morrer. Qual a alternativa, senão apelar à intervenção da boa Amizade?

Das almas puras pura Divindade,

Escuta-me benigna: dize, a Morte

Não poupará Fileno?... Céus! Piedade!

Dize-me, acaso a desabrida sorte,

Antes que eu desça à fria sepultura

Desferirá contra ele o final corte?

\section{$[\ldots]$}

Deusa que imperas sobre o peito nosso,

Ouve os meus rogos: assim cante a Terra

Sempre louvores ao império vosso.

Trata-se, pois, de uma elegia antes da hora, em que a tristeza se insinua por antecipação: o poeta não está triste (muito pelo contrário), mas teme vir a estar, e não por sentir-se ele mesmo apaixonado, mas por temer que o amor de outrem leve à cova o amigo, âncora da sua estabilidade emocional. É esse medo de perder o paraíso e voltar à conhecida angústia que produz a entrada dissonante do poema, em que a alegria de viver é rapidamente posta em cheque, pois tudo entre os mortais é efêmero, e o poeta pressente o fim dos seus prazeres:

Quanto é doce existir! Quanta doçura

Em ti encerras, preciosa vida,

Inda mesmo em momentos de amargura!

Sagrados Deuses, e hei de ver perdida

Esta fonte de bens e de prazeres,

Entre as garras da morte enfurecida?...

Não vos invejo, soberanos Seres,

Os bens que possuis; só vos invejo

O não teres receio de os perderes. 
A Elegia à amizade tangencia dois temas historicamente importantes para o gênero, o amor e a morte, mas não se detém exclusivamente sobre nenhum deles. Ela não é propriamente uma elegia erótica, pois quem escreve é o amigo daquele que sofre a paixão elegíaca; também não é uma elegia fúnebre, pois Fileno continua vivo e a alegria, até o momento, soberana. Quem não dirá, então, que a composição do Padre Caldas é um poema que teme tornar-se elegia, mas que já se apresenta, por antecipação, como aquilo que quer evitar?

\section{Considerações FinAIS}

Busquei falar da Elegia à amizade, escrita pelo padre Caldas, sem a intenção de esgotar a sua análise ou propor interpretações definitivas, mas abrir caminho a novos pesquisadores interessados na obra de Sousa Caldas e, quando muito, chamar a atenção para a existência de características ainda desconhecidas ou pouco exploradas em nossa poesia neoclássicas. Meu objetivo, modestíssimo, foi tão somente mostrar que a composição de Caldas, posta contra o panorama histórico das outras elegias até então publicadas em latim e português, se destaca por um manejo especial dos atributos associados ao gênero e por uma abordagem inédita da amizade como alternativa mais sadia ao amor, aqui identificado com o sofrimento. Será isso resultado de um deliberado projeto de atualização do gênero? Será uma tentativa de reatar os laços entre a sorumbática elegia neoclássica e sua multifacetada gênese latina? Receio não estar em condições de responder peremptoriamente a essas questões - que outros acadêmicos as ruminem e desenvolvam algures.

É preciso acrescentar que não tive a intenção de fazer uma crítica valorativa ao poema do padre Caldas. Não pretendi, destacando essa elegia do seu contexto e salientando a sua relação original com a tradição elegíaca, reconhecê-la como uma obra de arte excepcional, pois ela não o é senão nisso que busquei frisar. A Elegia à amizade foi publicada sem ruídos, e assim também passou, silenciosa, pela história da poesia brasileira. Isso não significa que ela merece o ostracismo crítico. A história se faz com detalhes. Tem-se muito frequentemente dito que mencionar uma obra é já, pela simples seleção, um ato valorativo. Não se pode razoavelmente discordar dessa proposição. Uma história coletiva e total da literatura, no entanto, não deve se esquivar de obras menores e inexpressivas, por mais insignificantes que sejam suas contribuições, apenas por recear atribuir-lhes um valor imerecido. Estudar essas peças obscuras (e não as gabar de graça, está claro) é um compromisso do pesquisador, e é buscando assumi-lo que aqui estudei, de modo tanto quanto sumário, essa pequena composição de um poeta quase esquecido. 


\section{REFERÊNCIAS}

AMORES DE OVÍDIO. A Águia: diário político, literário, analítico e mercantil. Número 61. Portugal, 23 set., 1834, p. 243.

CALDAS, Antônio Pereira de Sousa. Poesias sacras e profanas do Reverendo Antônio Pereira de Sousa Caldas. Tomo Segundo. Paris: Oficina de P. N. Rougeron, 1821.

CAMINHA, Pedro de Andrade. Poesias de Pedro de Andrade Caminha, mandadas publicar pela Academia Real das Ciências de Lisboa. Lisboa: Oficina da Academia Real das Ciências de Lisboa, 1791.

CASTILHO, Júlio de. Estudos biográfico-literários. In: FERREIRA, Antônio. Antônio Ferreira: poeta quinhentista. Tomo I. Rio de Janerio: Garnier; Paris: E. Belhatte, 1875.

FARIA, Eduardo de. Novo dicionário da língua portuguesa. Rio de Janeiro: Tipografia Imperial e Constitucional de J. Villeneuve, 1859 [1849].

FERREIRA, Antônio. Antônio Ferreira: poeta quinhentista. Tomo II. Rio de Janerio: Garnier; Paris: E. Belhatte, 1875.

FONSECA, Pedro José da. Elementos da poética, tratados de Aristóteles, de Horácio e dos mais célebres modernos. Lisboa: Oficina de Miguel Manescal da Costa, 1765.

FREIRE, Francisco José. Arte poética, ou regra da verdadeira poesia em geral e de todas as suas espécies principais, tratadas com juízo crítico. Lisboa: oficina de Francisco Luiz Ameno, 1749.

MASDEU, Juan Francisco. Arte poética fácil, diálogos familiares en que se enseña la poesía a cualquiera de mediano talento, de cualquiera sexo y edad. Valência: oficina de Burguete, 1801.

Recebido para publicação em: 19 abr. 2021. Aceito para publicação em: 21 ago. 2021. 